\title{
Groundwater upwelling occludes pores compared to top-down infiltration at the Burns fm., Mars
}

\author{
S. M. PerL ${ }^{1,2}$, M. MelWANI DASWANI ${ }^{1 *}$,
}

${ }^{1}$ Jet Propulsion Laboratory, California Institute of

Technology (*correspondence: daswani@jpl.caltech.edu)

${ }^{2}$ Mineral Sciences, Los Angeles Natural History Museum

\section{Introduction and Methods}

The Burns formation and associated deposits are a $\sim 3.5$ $\mathrm{Ga},>4 \times 10^{5} \mathrm{~km}^{3}$ sedimentary assemblage on Mars, formed by aqueous alteration of basaltic sandstone and later precipitation of sulfate salts ( 40 wt. \%). Finally, diagenesis precipitated hematite and partially dissolved sulfates leaving secondary porosity (Squyres et al., 2006; McLennan et al., 2005; Perl et al., in-prep). We test the fate of porosity during this final event with thermodynamic equilibrium code CHIMXPT (Reed 1998).

\section{Results and Discussion}

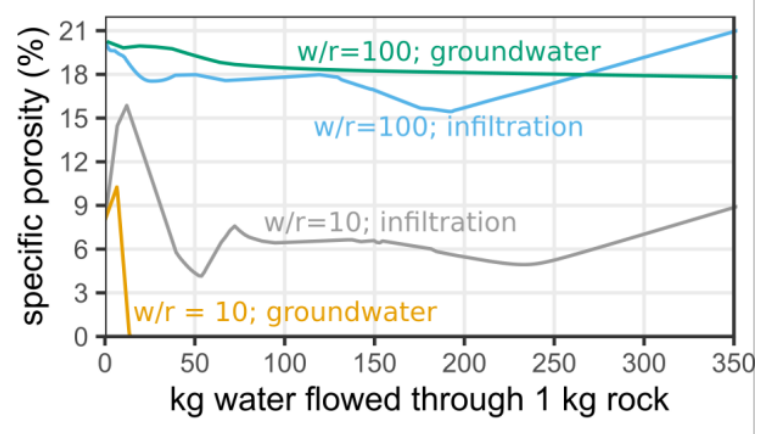

Assuming $\mathrm{W} / \mathrm{R}$ ratio $=10$ at the Burns formation. during the late diagenetic event (Fig. 1), groundwater upwelling occludes pores with secondary phyllosilicates for low amounts of fluid flowed through $\left(<20 \mathrm{~kg} \mathrm{H}_{2} \mathrm{O}\right.$ per $\mathrm{kg}$ rock; Fig. 1), preventing further fluid percolation with newly formed mineral sets from the previous fludic cycle. However, top-down weathering by water equilibrated with an early Mars atmosphere of 200 mbar $\mathrm{pCO}_{2}$ (Haberle et al., 2017) creates secondary pore space with infiltration (Fig. 1), dissolving and precipitating minerals along the flow path. Assuming W/R ratio $=100$, porosity can be maintained for both fluid infiltration and groundwater upwelling (Fig. 1). However, upwelling at high $\mathrm{W} / \mathrm{R}$ ratios requires significant recharge, implying a global hydrologic cycle, leading to extensive atmospheric carbon drawdown (Kite and Melwani Daswani, 2019), inconsistent with climate models (Haberle et al., 2017), suggesting that the final diagenetic event may have been top-down weathering instead. 